\title{
The Effect of Different Percent Liquid Addition and Wet Mix Time with Different Liquid Mix Cycle Time Setting on Uniformity of Mix
}

\author{
M Saensukjaroenphon ${ }^{1}$, CK Jones ${ }^{2}$, CH Fahrenholz ${ }^{3}$ and CR Stark ${ }^{1, *}$ \\ ${ }^{1}$ Department of Grain Science and Industry, Kansas State University, Manhattan, KS, USA \\ ${ }^{2}$ Department of Animal Sciences and Industry, Kansas State University, Manhattan, KS, USA \\ ${ }^{3}$ Phibro Animal Health Corporation, Manhattan, KS, USA
}

*Corresponding author: CR Stark, Department of Grain Science and Industry, Kansas State University, Manhattan, KS, USA, E-mail: crstark@ksu.edu

Received: 23 Apr, 2019 | Accepted: 15 May, 2019 | Published: 22 May, 2019

Citation: Saensukjaroenphon M, Jones CK, Fahrenholz CH, Stark CR (2019) The Effect of Different Percent Liquid Addition and Wet Mix Time with Different Liquid Mix Cycle Time Setting on Uniformity of Mix. J Anim Sci Res 3(3): dx.doi.org/10.16966/2576-6457.129

Copyright: (C) 2019 Saensukjaroenphon M, et al. This is an open-access article distributed under the terms of the Creative Commons Attribution License, which permits unrestricted use, distribution, and reproduction in any medium, provided the original author and source are credited.

\begin{abstract}
The liquid addition system is often designed to add liquid ingredients with the shortest application time in order to increase the batching capacity of the mixing process. The amount of liquid that is added into the mixer could affect the batch cycle time, especially, when there is a set wet mix time. The two most common settings in automated control systems are fixed total liquid mix time (liquid addition plus a wet mix time) and fixed wet mix time. The fixed total liquid mix time starts when a liquid pump is activated to add the liquid, whereas the fixed wet mix time setting starts after the liquid pumps stop. However, there is no data to determine which type of automated control system produces a uniform mix of liquid to dry feed. The objective of the experiments was to determine the effect of percent liquid addition, wet mix time and liquid mix cycle time setting on the uniformity of mix. Treatments were arranged in a $2 \times 3$ factorial: Experiment 1 treatments were fixed wet mix time (45 and $60 \mathrm{~s}$ ) and percent liquid addition (1.14\%, 2.27\% and 3.41\%); and Experiment 2 treatments were fixed total liquid mix time ( 45 and $60 \mathrm{~s}$ ) after liquid addition and percent liquid addition (1.14\%, $2.27 \%$ and 3.41\%). The results of Experiment 1 indicated the $45 \mathrm{~s}$ fixed wet mix time had a significantly higher \%CV as compared to the $60 \mathrm{~s}$ fixed wet mix time $(P=0.0467)$ but there was no interaction between fixed wet mix time and percent addition of $\mathrm{NaCl}$ solution $(P=0.5114)$. The results of Experiment 2 indicated an interaction between the percent addition of $\mathrm{NaCl}$ solution and the fixed total liquid mix time $(P=0.0221)$, and both percent addition of $\mathrm{NaCl}$ solution and fixed total liquid mix time affected the \%CV treatment $(P<0.0001$ and $P=0.0002$, respectively). The results of these experiments demonstrated that the liquid addition time and the percent of liquid addition affected the uniformity of mix. The uniformity of liquid application should be tested with the highest percent liquid addition.
\end{abstract}

Keywords: Liquid addition; Wet mix time; Mixer uniformity

Abbreviations: CV-Coefficient of variation; SBM-Soy bean meal; FW-Fixed wet mix time; FLT-Fixed total liquid mix time

\section{Introduction}

The number of liquid ingredients and amounts added to the mixer has increased over the last 10 years. Steen [1] reported liquid ingredient inclusion levels in North America, Europe and Asia ranged from $0.15-0.30 \%$ for methionine, $0.05-0.50 \%$ for choline chloride, $0.15-0.30 \%$ for lysine, $0-3 \%$ for fat or oil and $0.01 \%$ for enzymes. Each liquid may be added in separate lines or in a single line from a common liquid scale. The liquid addition times vary based on the percent of liquid applied and type of application system. The amount of liquids added to a mixer could affect the batch cycle time when the batch controller has a set wet mix time. The two most common settings in automated control systems are fixed total liquid mix time (liquid addition plus a wet mix time) and fixed wet mix time. The fixed total liquid mix time starts when a liquid pump is activated to add the liquid, whereas the fixed wet mix time setting starts after the liquid pump stops (Figure 1). The liquid addition time in the fixed wet mix time setting creates a variable batch cycle time. Therefore, liquid addition systems are designed to add liquid ingredients in the shortest time possible in order to increase the batching capacity of the mixing process. However, there is no data to determine which type of automated control systems produces a uniform mix of liquid to dry feed. Saensukjaroenphon, et al. [2] suggested there must be a minimum wet mix time after all liquids have been added to the mixer. Therefore, increasing the liquid addition time by adding more liquids in the mixer would decrease the wet mix time after liquid addition for the fixed total liquid mix time system. The objective of the experiments was to determine the effect of percent liquid addition, wet mix time and liquid mix cycle time setting on the uniformity of mix.

\section{Materials and Methods}

\section{Experiment 1}

Treatments were arranged in a $2 \times 3$ factorial of fixed wet mix time (45 and $60 \mathrm{~s}$ ) after liquid addition and percent liquid addition, which is grams of $\mathrm{NaCl}$ solution per 100 grams of dry feed (1.14\%, $2.27 \%$ 


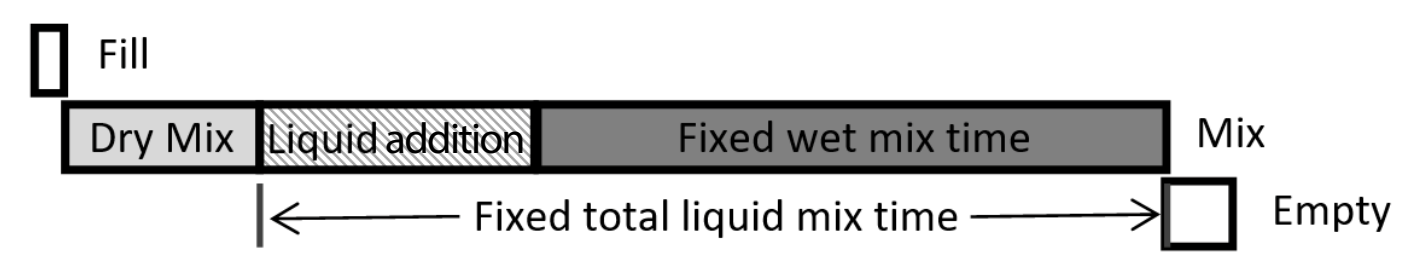

Figure 1: Illustration of the mixing cycle.

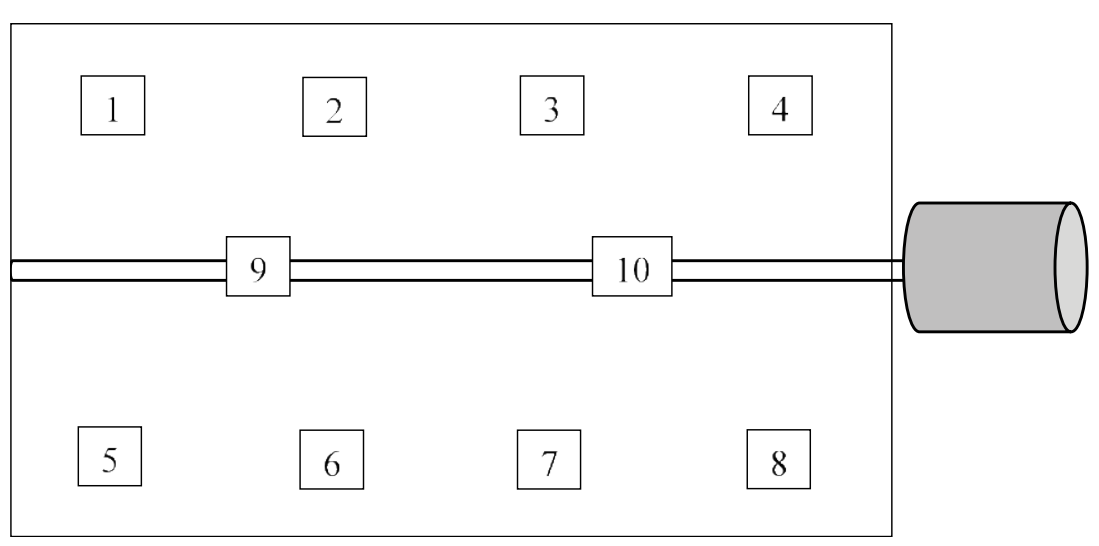

Figure 2: The sampling points of the mixer surface (top view).

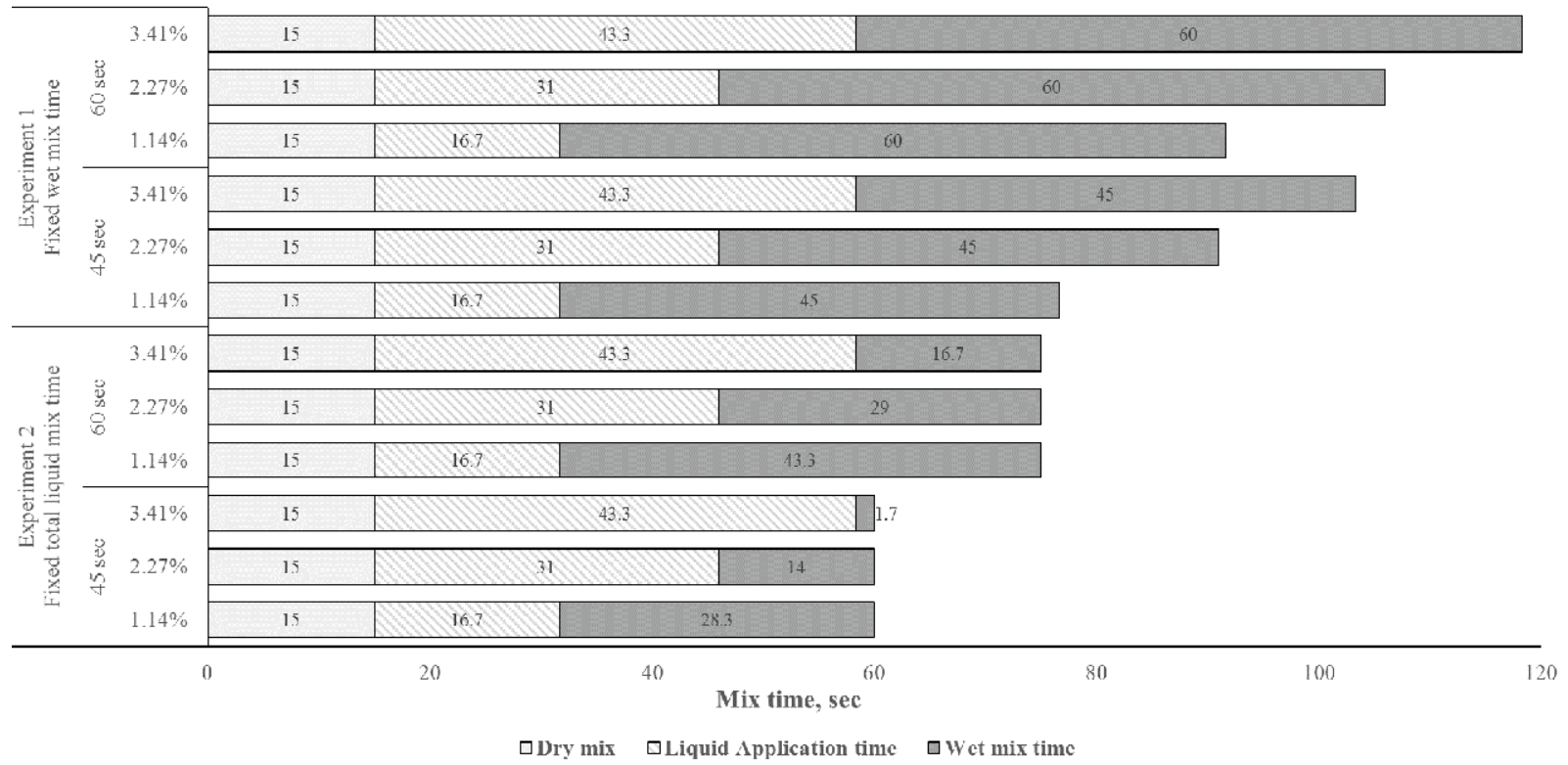

Figure 3: Illustration of the mix time of Experiments 1 and 2 for each treatment. 
Table 1: Effect of fixed wet mix time on the coefficient of variation (\%CV) of feed mixed and sprayed with different percent $\mathrm{NaCl}$ solution additions.

\begin{tabular}{|c|c|c|c|}
\hline Liquid addition (\%) & $\begin{array}{l}\text { Fixed wet mix } \\
\text { time (s) }\end{array}$ & $n$ & $\begin{array}{c}\text { Coefficient of } \\
\text { Variation }^{\left[{ }^{2]}\right.}, \mathrm{CV}(\%)\end{array}$ \\
\hline \multicolumn{4}{|l|}{ Interaction effects } \\
\hline 1.14 & 45 & 3 & 7.37 \\
\hline 1.14 & 60 & 3 & 6.06 \\
\hline 2.27 & 45 & 3 & 6.28 \\
\hline 2.27 & 60 & 3 & 5.3 \\
\hline 3.41 & 45 & 3 & 9.21 \\
\hline 3.41 & 60 & 3 & 6.01 \\
\hline SEM & & & 1.01 \\
\hline \multicolumn{4}{|l|}{ Main effect } \\
\hline 1.14 & & 6 & 6.72 \\
\hline 2.27 & & 6 & 5.79 \\
\hline 3.41 & & 6 & 7.61 \\
\hline \multirow[t]{4}{*}{ SEM } & & & 0.71 \\
\hline & 45 & 9 & $7.62^{\mathrm{a}}$ \\
\hline & 60 & 9 & $5.79^{\mathrm{b}}$ \\
\hline & SEM & & 0.58 \\
\hline \multicolumn{4}{|c|}{ P-value } \\
\hline \multicolumn{3}{|l|}{ Source of variation } & \\
\hline \multicolumn{3}{|c|}{ Percent liquid $\times$ Fixed wet mix time } & 0.5144 \\
\hline \multicolumn{3}{|l|}{ Percent liquid } & 0.2372 \\
\hline \multicolumn{3}{|l|}{ Fixed wet mix time } & 0.0467 \\
\hline
\end{tabular}

and $3.41 \%$ ) to determine the effect of liquid addition on uniformity of mix. A corn-soybean meal swine grower diet without salt was used for the experiment. A $230 \mathrm{~g} / \mathrm{kg} \mathrm{NaCl}$ solution was prepared by mixing $230 \mathrm{~g}$ of salt with $770 \mathrm{~g}$ of distilled water. The $27.2 \mathrm{~kg}$ of dry feed ingredients were added to a $0.056 \mathrm{~m}^{3}$ double ribbon mixer, $0.34 \mathrm{~m}$ wide $\times 0.66 \mathrm{~m}$ long with $50 \mathrm{rpm}$ drive speed (Hayes and Stolz model HP2SSS-0106, Fort Worth, TX). The feed ingredients were dry mixed for $15 \mathrm{~s}$ followed by the addition of $0.31,0.62$ and $0.93 \mathrm{~kg}$ of a $230 \mathrm{~g} / \mathrm{kg}$ $\mathrm{NaCl}$ solution. The $230 \mathrm{~g} / \mathrm{kg} \mathrm{NaCl}$ solutions were applied to dry feed in the mixer by using a hand-held sprayer (model 26329, Orscheln Farm \& Home LLC, Moberly, MO) with a nozzle (model TP11006, Teejet Technologies, Springfield, IL). Samples of $30 \mathrm{~g}$ each were scooped out from the mixture surface at ten individual points
Table 2: Effect of fixed total liquid mix time on the coefficient of variation $(\% \mathrm{CV})$ of feed mixed and sprayed with different percent $\mathrm{NaCl}$ solution additions.

\begin{tabular}{|c|c|c|c|}
\hline Liquid addition (\%) & $\begin{array}{l}\text { Fixed total liquid } \\
\text { mix time (s) }\end{array}$ & $n$ & $\begin{array}{c}\text { Coefficient of Variation }{ }^{[a]} \text {, } \\
\text { CV (\%) }\end{array}$ \\
\hline \multicolumn{4}{|l|}{ Interaction effects } \\
\hline 1.14 & 45 & 3 & $14.58^{\mathrm{a}, \mathrm{b}}$ \\
\hline 1.14 & 60 & 3 & $6.26^{\mathrm{a}}$ \\
\hline 2.27 & 45 & 3 & $17.73^{\mathrm{a}, \mathrm{b}}$ \\
\hline 2.27 & 60 & 3 & $13.20^{\mathrm{a}, \mathrm{b}}$ \\
\hline 3.41 & 45 & 3 & $42.25^{c}$ \\
\hline 3.41 & 60 & 3 & $21.47^{b}$ \\
\hline SEM & & & 2.6 \\
\hline \multicolumn{4}{|l|}{ Main effect } \\
\hline 1.14 & & 6 & $10.42^{x}$ \\
\hline 2.27 & & 6 & $15.46^{\mathrm{x}}$ \\
\hline 3.41 & & 6 & $21.86^{Y}$ \\
\hline \multirow[t]{4}{*}{ SEM } & & & 1.84 \\
\hline & 45 & 9 & $24.85^{\mathrm{K}}$ \\
\hline & 60 & 9 & $13.64^{\mathrm{L}}$ \\
\hline & SEM & & 1.5 \\
\hline \multicolumn{4}{|c|}{ P-value } \\
\hline \multicolumn{3}{|l|}{ Source of variation } & \\
\hline \multicolumn{3}{|c|}{ Percent liquid $\times$ Fixed total liquid mix time } & 0.0221 \\
\hline \multicolumn{3}{|l|}{ Percent liquid } & $<0.0001$ \\
\hline \multicolumn{3}{|l|}{ Linear } & $<0.0001$ \\
\hline \multicolumn{3}{|l|}{ Quadratic } & 0.027 \\
\hline \multicolumn{3}{|c|}{ Fixed total liquid mix time } & 0.0002 \\
\hline \multicolumn{4}{|c|}{$\begin{array}{l}\text { [a] Means within an interaction effect followed by different letters (a } \\
\text { to } c \text { ) are significantly different }(P \leq 0.05) \text {. Means within a main effect } \\
\text { of percent liquid addition by different letters }(X, Y) \text { are significantly } \\
\text { different ( } P \leq 0.01) \text {, and means within a main effect of fixed total liquid } \\
\text { mix time followed by different letters }(K, L) \text { are significantly different ( } P \\
\leq 0.01 \text { ). }\end{array}$} \\
\hline
\end{tabular}

in the mixer (Figure 2) after the feed was mixed for 45 and 60 s fixed wet mix time (Figure 3 ). Diets were mixed 3 separate times to provide 3 replicates per treatment. Samples were analyzed for salt concentration.

The salt concentration in the collected samples was determined with the Quantab ${ }^{\star}$ chloride titrator method [3]. A $10 \mathrm{~g}$ sample was weighed into a cup and $90 \mathrm{~g}$ of hot distilled water $\left(60^{\circ} \mathrm{C}\right)$ was added to the cup. The mixture was stirred for $30 \mathrm{~s}$, allowed to rest for $60 \mathrm{~s}$ and stirred for another $30 \mathrm{~s}$. A folded filter paper was placed into the cup and the Quantab strip was inserted into the liquid at the bottom of the filter paper. The coefficient of variation $(\mathrm{CV})$ was calculated by dividing the standard deviation by the average of 10 samples and then multiplied by 100 for each batch of feed. 
Table 3: Effect of liquid mix cycle time setting on the coefficient of variation (\%CV) of feed mixed and sprayed with different percent $\mathrm{NaCl}$ solution additions.

\begin{tabular}{|c|c|c|c|}
\hline Liquid addition (\%) & Time $^{[a]}$ & $n$ & Coefficient of Variation ${ }^{[b]}$, CV (\%) \\
\hline \multicolumn{4}{|l|}{ Interaction effects } \\
\hline 1.14 & FTL45 & 3 & $14.58^{\mathrm{A}, \mathrm{B}, \mathrm{C}}$ \\
\hline 1.14 & FTL60 & 3 & $6.26^{A}$ \\
\hline 1.14 & FW45 & 3 & $7.37^{A, B}$ \\
\hline 1.14 & FW60 & 3 & $6.06^{A}$ \\
\hline 2.27 & FTL45 & 3 & $17.73^{\mathrm{B}, \mathrm{C}}$ \\
\hline 2.27 & FTL60 & 3 & $13.20^{\mathrm{A}, \mathrm{B}, \mathrm{C}}$ \\
\hline 2.27 & FW45 & 3 & $6.28^{A}$ \\
\hline 2.27 & FW60 & 3 & $5.30^{\mathrm{A}}$ \\
\hline 3.41 & FTL45 & 3 & $42.25^{\mathrm{D}}$ \\
\hline 3.41 & FTL60 & 3 & $21.47^{c}$ \\
\hline 3.41 & FW45 & 3 & $9.21^{\mathrm{A}, \mathrm{B}}$ \\
\hline 3.41 & FW60 & 3 & $6.01^{A}$ \\
\hline SEM & & & 1.98 \\
\hline \multicolumn{4}{|l|}{ Main effect } \\
\hline 1.14 & & 12 & $8.57^{x}$ \\
\hline 2.27 & & 12 & $10.62^{x}$ \\
\hline 3.41 & & 12 & $19.73^{Y}$ \\
\hline \multirow[t]{6}{*}{ SEM } & & & 0.99 \\
\hline & FTL45 & 9 & $24.85^{\mathrm{K}}$ \\
\hline & FTL60 & 9 & $13.64^{\mathrm{L}}$ \\
\hline & FW45 & 9 & $7.62^{\mathrm{M}}$ \\
\hline & FW60 & 9 & $5.79^{\mathrm{M}}$ \\
\hline & SEM & & 1.14 \\
\hline \multicolumn{4}{|c|}{ P-value } \\
\hline \multicolumn{4}{|l|}{ Source of variation } \\
\hline \multicolumn{3}{|c|}{ Percent liquid $\times$ Application } & $<0.0001$ \\
\hline \multicolumn{3}{|l|}{ Percent liquid } & $<0.0001$ \\
\hline \multicolumn{3}{|l|}{ Linear } & $<0.0001$ \\
\hline \multicolumn{3}{|l|}{ Quadratic } & 0.0076 \\
\hline \multicolumn{3}{|l|}{ Application } & $<0.0001$ \\
\hline \multicolumn{4}{|c|}{$\begin{array}{l}\text { [a] } \mathrm{FTL}=\text { fixed total liquid mix time, } \mathrm{FW}=\text { fixed wet mix time, } 45=45 \mathrm{~s} \text { and } \\
60=60 \mathrm{~s} \text {. } \\
\text { [b] Means within an interaction effect followed by different letters ( } \mathrm{A} \\
\text { to } \mathrm{D} \text { ) are significantly different }(P \leq 0.01 \text { ). Means within a main effect } \\
\text { of percent liquid addition by different letters }(\mathrm{X}, \mathrm{Y}) \text { are significantly } \\
\text { different ( } P \leq 0.01) \text {, and means within a main effect of time followed by } \\
\text { different letters (K to M) are significantly different }(P \leq 0.01 \text { ). }\end{array}$} \\
\hline
\end{tabular}

\section{Experiment 2}

Treatments were arranged in a $2 \times 3$ factorial of fixed total liquid mix time (45 and $60 \mathrm{~s}$ ) and percent liquid addition (1.14\%, $2.27 \%$ and $3.41 \%$ ) to determine the effect of liquid addition on uniformity of mix. Mixing of the dry ingredients and application of the $230 \mathrm{~g} / \mathrm{kg}$ $\mathrm{NaCl}$ solution were the same as Experiment 1. Samples of $30 \mathrm{~g}$ each were scooped out from the mixture surface at ten individual points in the mixer (Figure 2) after the feed was mixed for the total time of 60 and 75 s (Figure 3). Diets were mixed 3 separate times to provide 3 replicates per treatment. Samples were analyzed for salt concentration with Quantab ${ }^{\circledR}$ strips as previously described in Experiment 1.

\section{Statistical analysis}

Data were analyzed as a factorial treatment design for all experiments. Experiment 1 treatments were arranged in a $2 \times 3$ factorial of fixed wet mix time (45 s, FW45 and $60 \mathrm{~s}, \mathrm{FW} 60)$ and percent liquid addition $(1.14 \%, 2.27 \%$ and $3.41 \%)$ to determine the effect of liquid addition on uniformity of mix. Experiment 2 treatments were arranged in a $2 \times 3$ factorial of fixed total liquid mix time ( $45 \mathrm{~s}$, FTL45 and $60 \mathrm{~s}$, FTL60) and percent liquid addition $(1.14 \%, 2.27 \%$ and $3.41 \%)$ to determine the effect of liquid addition on uniformity of mix. The fixed wet mix time and fixed total liquid mix time factors from Experiments 1 and 2, respectively, were combined as a liquid mix cycle time setting factor. The combination of Experiments 1 and 2 treatments were arranged in a $4 \times 3$ factorial of liquid mix cycle time setting (FTL45, FTL60, FW45 and FW60) and percent liquid addition (1.14\%, 2.27\% and $3.41 \%$ ) to determine the effect of liquid addition on uniformity of mix. There were 3 replicates per treatment. Data were analyzed using the GLIMMIX procedure of SAS. Means were separated by least squares means adjustment for Bonferroni's multiple comparisons. Results were considered significant at $P \leq 0.05$.

\section{Results and Discussion}

The results of Experiment 1 (Table 1) indicated that increasing fixed wet mix time improved the $\% \mathrm{CV}$. There was no interaction between fixed wet mix time and percent addition of $\mathrm{NaCl}$ solution $(P=0.5114)$. The average actual application times for 1.14, 2.27 and $3.41 \%$ liquid additions were 16.7, 31.0 and $43.3 \mathrm{~s}$, respectively. The percent addition of $\mathrm{NaCl}$ solution was not significantly different on \%CV $(P=0.2372)$. However, the $45 \mathrm{~s}$ fixed wet mix time had a significantly higher $\% \mathrm{CV}$ as compared to the 60 s fixed wet mix time $(P=0.0467)$, but the $C V$ was less than $10 \%$.

The results of Experiment 2 (Table 2) indicated an interaction between the percent addition of $\mathrm{NaCl}$ solution and the fixed total liquid mix time $(P=0.0221)$. The $1.14 \%$ of $\mathrm{NaCl}$ solution addition combined with the $60 \mathrm{~s}$ fixed total liquid mix time resulted in the lowest \%CV $(6.26 \%)$ as a result of the longest wet mix time (43.3 s). In contrast, the $3.41 \%$ of $\mathrm{NaCl}$ solution addition with $45 \mathrm{~s}$ fixed total liquid mix time had the highest effect on \%CV (42.25\%) due to the shortest wet mix time $(1.7 \mathrm{~s})$. The main effects indicated that both percent addition of $\mathrm{NaCl}$ solution and fixed total liquid mix time affected the \%CV. The $45 \mathrm{~s}$ fixed total liquid mix time had significantly higher \%CV than $60 \mathrm{~s}$ $(P=0.0002)$. There was a quadratic increase in $\% \mathrm{CV}$ as the percentages of added $\mathrm{NaCl}$ solution increased $(P=0.0270)$. The highest $\% \mathrm{CV}$ occurred when the $3.41 \%$ of the $230 \mathrm{~g} / \mathrm{kg} \mathrm{NaCl}$ solution was applied to the feed $(P<0.0001)$.

The results of combined data for Experiments 1 and 2 (Table 3) indicated an interaction between percent $\mathrm{NaCl}$ solution addition and liquid mix cycle time setting $(P<0.0001)$. The $3.41 \% \mathrm{NaCl}$ solution addition with fixed wet mix (FW45 and FW60) treatments were 
less than $10 \%$ CV (9.21 and 6.01\%, respectively). However, for fixed total liquid mix times of $45 \mathrm{~s}$ and $60 \mathrm{~s}$ (FTL45 and FTL60) the \%CV was above the target ( 42.25 and $21.47 \%$, respectively). The results of the $2.27 \% \mathrm{NaCl}$ solution addition with $45 \mathrm{~s}$ and $60 \mathrm{~s}$ fixed wet mix time (FW45 and FW60) were similar to the $3.41 \%$. The FW45 and FW60 treatments were less than $10 \%$ CV, whereas FTL45 and FTL60 treatments were greater than $10 \% \mathrm{CV}$ (17.73 and $13.20 \%$, respectively). The results of the $1.14 \% \mathrm{NaCl}$ solution addition with $45 \mathrm{~s}$ and 60 s fixed wet mix time (FW45 and FW60) were similar to the 2.27 and $3.41 \%$ addition results. However, there was a difference in the FTL45 and FTL60 treatments. The data suggested that there was sufficient wet mix time after the $1.14 \%$ solution was applied for the FTL60 treatment but not enough wet mix time for the FTL45 treatment. The FTL60 treatment actually had a $43.3 \mathrm{~s}$ wet mix time due to the short application time of $1.14 \%$ liquid addition. The $\% \mathrm{CV}$ were not different as the percent of the $\mathrm{NaCl}$ solution was increased from $1.14 \%$ to $2.27 \%$ and the $\% \mathrm{CV}$ increased as the percent of $\mathrm{NaCl}$ solution was increased from 1.14 and 2.27 to $3.41 \%$ (quadratic; $P=0.0076)$. The liquid mix cycle time setting significantly affected $\% \mathrm{CV}(P<0.0001)$. The short liquid mix cycle time setting had a greater effect on \%CV than the longer cycle time.

The two experiments had different results due to how the wet time was controlled. In Experiment 1, the liquid addition time was not counted in the wet mix time, whereas in Experiment 2 the liquid addition time was counted in the total liquid mix time. For instance, assume a mixing cycle of a batching system consists of 45 $\mathrm{s}$ dry ingredient fill time, $15 \mathrm{~s}$ dry mix, $20 \mathrm{~s}$ liquid addition time, $45 \mathrm{~s}$ wet mix time and $15 \mathrm{~s}$ empty time. If the wet mix time setting of the batching control is set as fixed wet mix time (Experiment 1), then the mixing cycle is $140 \mathrm{~s} / \mathrm{batch}$ and the mixer efficiency is 25 batches $/ \mathrm{hr}$. The number of batches per hour is decreased as the liquid addition time is increased. In contrast, when the wet mix time setting of the batching control is set as fixed total liquid mix time (Experiment 2), the mixing cycle is $120 \mathrm{~s} / \mathrm{batch}$ and the mixer efficiency is 30 batches/ $\mathrm{hr}$. The number of batches per hour is stable when the liquid addition time is changed. However, a mixing uniformity test is required for the fixed wet mix time setting if the \% liquid addition increases and for the fixed total liquid mix time setting if the \% liquid addition or liquid addition time increases based on the previous test.

\section{Conclusion}

The results of these experiments demonstrated that both liquid cycle time and the percent of liquid addition affected the uniformity of mix. The uniformity of liquid application should be tested with the highest percent of liquid addition and different wet mix times in order to establish the wet mix time. The efficiency of the mixing process will be increased if the liquid application time is decreased. The fixed total liquid mix time computer set-up has a constant mixing cycle time, whereas the fixed wet mix time is variable based on the time required to apply liquids to the formula.

\section{References}

1. Steen P (2013) Liquid Application at the Feed Mill: Macro and Micro Ingredients, Pre and Post Pelleting Application.

2. Saensukjaroenphon $\mathrm{M}$, Evans $\mathrm{CE}$, Jones $\mathrm{CK}$, Fahrenholz $\mathrm{CH}$, Paulk CB, et al. (2019) The Effect of Liquid Application Time and Wet Mix Time with Different Mixer Types on Uniformity of Mix. J Anim Sci Res 3.

3. Stark CR, Saensukjaroenphon M (2017) Testing Mixer Performance. Bulletin MF-3393, Kansas State University Agricultural Experiment Station and Cooperative Extension Service, Manhattan, KS: Kansas State University. 